\title{
A Permanent Magnet Generator for Energy Conversion from Marine Currents: No Load and Load Experiments
}

\author{
Karin Thomas, Mårten Grabbe, Katarina Yuen, and Mats Leijon \\ The Swedish Centre for Renewable Electric Energy Conversion and Department of Engineering Sciences, Uppsala University, \\ P.O. Box 534, 75121 Uppsala, Sweden
}

Correspondence should be addressed to Karin Thomas, karin.thomas@angstrom.uu.se

Received 4 April 2012; Accepted 3 May 2012

Academic Editors: S. Li, Y.-C. Lin, Z. Oktay, and S. Santoso

Copyright ( 2012 Karin Thomas et al. This is an open access article distributed under the Creative Commons Attribution License, which permits unrestricted use, distribution, and reproduction in any medium, provided the original work is properly cited.

This paper presents experiments and measurements on a low speed permanent magnet cable wound generator for marine current energy conversion. Measurements were made for no load and nominal load (4.44 $\Omega$ /phase) conditions at nominal speed ( $10 \mathrm{rpm})$. For either load condition, the magnetic fields in the air gap were also measured. The measurements on the generator were compared with the corresponding finite element method simulations used to design the machine. It is shown in the paper that measurements and corresponding case simulations show good agreement. At nominal speed, the measured and simulated load voltages (nominal load) differ less than 1\% for the rms values and less than $5 \%$ for peak values. At no load, measured and simulated voltages had larger differences, that is, $<9 \%$ for rms values and $<5 \%$ for peak values. Harmonic analyses of measured and simulated phase voltages and currents show only the presence of third harmonics. The percentage of harmonics in the measured data was comparable with the corresponding predictions of the simulations. The discussions and results presented in the paper could be beneficial for future design of efficient and reliable marine current energy converter systems.

\section{Introduction}

For energy resources such as wind, wave, and tidal power, it may be beneficial to adapt the generators to the nature of the resource. For wind and wave power, several generator designs have been presented by both industry and academia [1-9]. So far, published material concerning generators designed specifically to match the tidal current regime have been less abundant. However, in recent years interesting generator topologies suited for marine current turbines have been suggested in literature, for example [9-12]. Authors of this paper have previously discussed the advantages of having a variable speed permanent magnet $(\mathrm{PM})$ direct drive generator for extracting energy from tidal and marine currents and presented simulations, for example [13]. Some of the main design objectives were to achieve a high efficiency at low speeds to exclude the use of a gearbox, and to maintain a low load angle to allow for electrical control and breaking of the turbine at high flow velocities.

To study the electrical performance of such a low speed machine, a prototype generator with nominal ratings $5 \mathrm{~kW}$,
$150 \mathrm{~V}, 10 \mathrm{rpm}$, and $10 \mathrm{~Hz}$ was designed and constructed for laboratory tests, see Figure 1 and Table 1. A thorough presentation of the electrical and mechanical design of the generator can be found in [14]. The experimental results presented here validate the simulations previously presented in $[13,14]$. The generator is designed for a system with a vertical axis turbine with fixed blade pitch and a directly driven generator [15]. This requires a generator that can be efficiently operated at different speeds and loads.

In this paper, results from no load and nominal load operation are presented. Voltages and currents are measured, as well the magnetic field in the air gap. These measurements form a reference for comparisons with the corresponding finite element method (FEM) simulations used for the initial design of the generator [14]. Simulations of the generator performance at variable speed operation are also presented to highlight its ability to electrically control and brake the turbine at high flow velocities that can occur in rivers or tidal currents. Such electrical power control is intended to replace mechanical systems for power control, such as blade pitch mechanisms and mechanical brakes. 


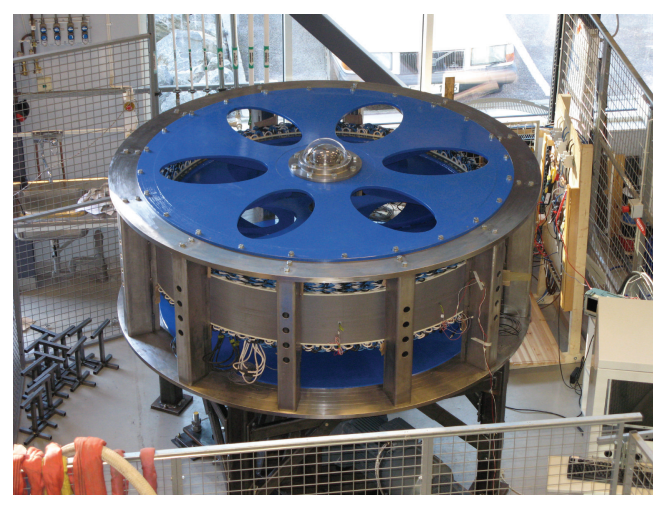

Figure 1: The $5 \mathrm{~kW}$ experimental generator.

TABLE 1: Generator design parameters.

\begin{tabular}{lc}
\hline Parameter & Value \\
\hline Power & $5 \mathrm{~kW}$ \\
Line voltage & $150 \mathrm{~V}$ \\
Nominal speed & $10 \mathrm{rpm}$ \\
Frequency & $10 \mathrm{~Hz}$ \\
Outer diameter & $2000 \mathrm{~mm}$ \\
Inner diameter & $1835 \mathrm{~mm}$ \\
Air gap & $10.5 \mathrm{~mm}$ \\
Slots per pole and phase & $7 / 5$ \\
Cables per slot & 6 \\
Magnet width & $32 \mathrm{~mm}$ \\
Magnet thickness & $13 \mathrm{~mm}$ \\
Stator axial length & $294 \mathrm{~mm}$ \\
Stacking factor & 0.956 \\
Resistance per phase & $0.47 \Omega$ \\
Load & $4.44 \Omega$ per phase \\
\hline
\end{tabular}

The load tests were carried out primarily to evaluate the performance of the machine under nominal load conditions. Harmonic analyses of the measured data are presented and possible reasons for the electromagnetic losses and harmonics in the experimental machine are discussed. The results and discussions presented in the paper could be useful for future design and construction of generators for marine current energy conversion.

\section{Finite Element Generator Model}

For electromagnetic analysis and design of electrical machines, FEM has emerged as more or less a standard tool. The generator presented in this paper has been analyzed in the finite element environment ACE (ACE, Modified Version 3.1, $\mathrm{ABB}$ common platform for field analysis and simulations, $\mathrm{ABB}$ Corporate Research Centre, $\mathrm{ABB} \mathrm{AB}$, Corporate Research, 72178 Västerås, Sweden), based on a two dimensional field model of an axial cross-section of the generator.

After the generator geometry is decided, the different subdomains of the calculation geometry are allocated

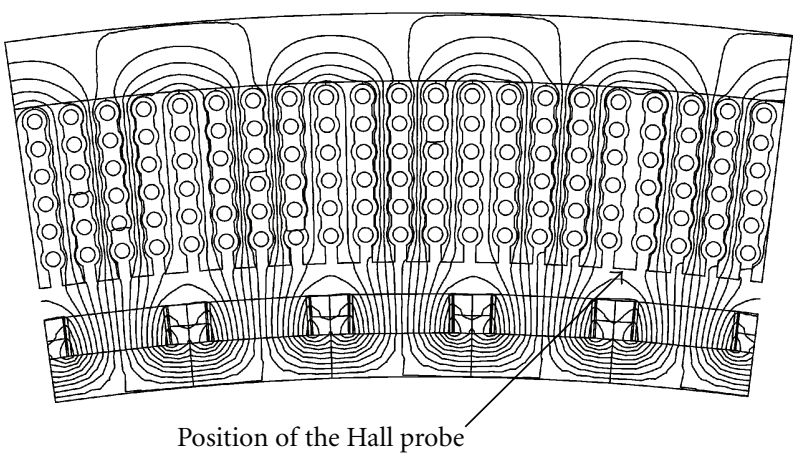

FIGURE 2: Location of the Hall probe (magnetic field measurements) and the simulated magnetic field distribution in one section.

material properties such as electric conductivity, $\sigma$, and relative magnetic permeability, $\mu_{r}$. Nonlinear ferromagnetic material properties of the stator steel are represented by a single-valued $\mathrm{BH}$ curve. Three-dimensional end effects are taken into account by introducing coil end impedances in the circuit equations of the stator windings and the permanent magnets are modeled by surface current sources.

Rotating machines usually present symmetry conditions that allow for a reduction of the necessary calculation geometry. In this case, a fractional winding with $7 / 5$ slots per pole and phase is used, and thus the calculation geometry includes a section of five poles and 21 stator slots (see Figure 2).

The complete generator model is described by a combined set of field and circuit equations. The magnetic vector potential inside the generator is described by

$$
\sigma \frac{\partial A_{z}}{\partial t}+\nabla \cdot\left(\frac{1}{\mu_{0} \mu_{r}} \nabla A_{z}\right)=-\sigma \cdot \frac{\partial V}{\partial z}
$$

where $\sigma$ is the conductivity, $\mu$ is the permeability, $A_{z}$ is the axial component of the magnetic vector potential, and $V$ is the applied potential (thus the right hand term denotes the applied current density).

The circuit equations are described by

$$
\begin{gathered}
I_{a}+I_{b}+I_{c}=0, \\
U_{a b}=U_{a}+R_{s} I_{a}+L_{s}^{\text {end }} \frac{\partial I_{a}}{\partial t}-U_{b}-R_{s} I_{b}-L_{s}^{\text {end }} \frac{\partial I_{b}}{\partial t}, \\
U_{c b}=U_{c}+R_{s} I_{c}+L_{s}^{\text {end }} \frac{\partial I_{c}}{\partial t}-U_{b}-R_{s} I_{b}-L_{s}^{\text {end }} \frac{\partial I_{b}}{\partial t},
\end{gathered}
$$

where $I_{a}, I_{b}$, and $I_{c}$ are the conductor currents in the three phases $a, b$, and $c$, respectively. $U_{a b}$ and $U_{c b}$ are the terminal line voltages and $U_{a}, U_{b}$, and $U_{c}$ are the phase voltages obtained from solving the field equation. $R_{s}$ is the winding resistance and $L_{s}^{\text {end }}$ describes the coil end inductance. Furthermore, it should be noted that frictional losses in the bearings and windage losses are neglected while evaluating the efficiency due to the low rotational speed and high torque. 


\section{Generator Parameters}

Before performing the tests on the machine, some of the electrical circuit parameters and geometrical parameters of the experimental machine were measured under standstill conditions. The resistance and inductance per phase of the winding is $0.475 \Omega$ and $11.5 \mathrm{mH}$. These values were measured using a precision bridge [16]. For a full description of the generator geometry, see [14].

A fractional winding is used and the number of slots per pole per phase is 1.4 , hence the angular displacement between the slots is $\beta=42.8^{\circ}$ and the phase spread angle is $60^{\circ}$. Hence, the distribution factor is $k_{d}=0.977$. In the present case the pole pitch is 4.2 slots. The designed machine is short pitched by $35.5^{\circ}$ and the pitch factor is $k_{p}=0.952$.

For safety, and to avoid possible floating conditions of either generator or the load, the neutral of both the generator and the load are shorted and grounded to the common power supply ground of the motor drive unit. Both the generator and the loads are $\mathrm{Y}$ connected.

\section{Generator Performance}

4.1. No Load Experiments. The generator no load test was carried out at the nominal speed of $10 \mathrm{rpm}$. Once the generator had reached a constant speed, the magnetic field in the air gap was measured on a stator tooth using a 7010 Gauss/Tesla meter [17], that is, the Hall probe was fixed at one stator tooth perpendicular to the magnetic flux. Note that there are two components of magnetic fields in the air gap, namely, normal, $B_{n}$, and tangential, $B_{t}$, components. Only the normal component was measured by the Hall probe. The simulated value for the $B$-field is taken at a point $1 \mathrm{~mm}$ in front of a stator tooth as shown in Figure 2, to match the position of the Hall probe during measurements. Also shown in Figure 2 are the magnetic field lines in one section of the machine. The measured normal component of the no load air gap magnetic fields is shown in Figure 3 together with the magnetic field predicted by the simulations. Simulations show that the maximum normal component and tangential components of the magnetic field in the air gap are around $0.6 \mathrm{~T}$ and $0.15 \mathrm{~T}$, respectively. The difference in the peak normal component of the measured and calculated magnetic fields is about $6 \%$. The force per unit area in the air gap at no load is calculated to $65 \mathrm{kN} / \mathrm{m}^{2}$ using the simulation tool.

The no load phase voltages were measured for all three phases and they all were balanced and phase shifted by $120^{\circ}$. Hence only the voltage for one phase is shown in Figure 4 together with the voltage predicted by the simulations. The differences in the rms value of simulated and measured voltages are shown in Table 2. It is found that the rms value of the simulated voltages are about $9 \%$ higher when compared with the measurements. This is most likely due to measurement uncertainties and modeling inaccuracies regarding for example end effects. Furthermore, the small differences in axial length of the rotor and the stator due to constructional errors are not taken into account in the modeling of the generator. The voltages were measured using three Tektronix P2220 voltage probes [18].

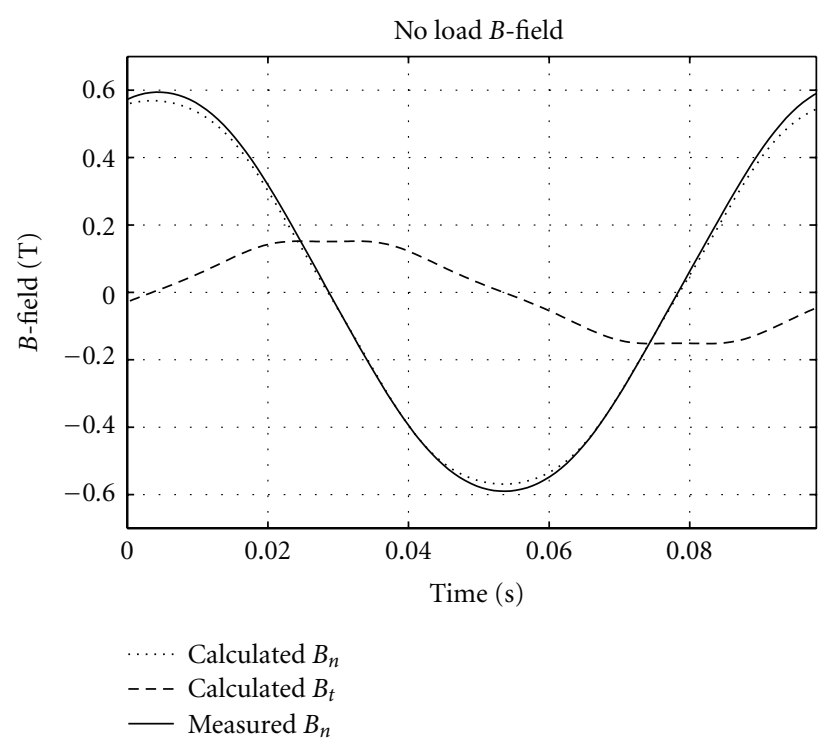

Figure 3: The magnetic field components in the air gap at no load and nominal speed of $10 \mathrm{rpm}$.

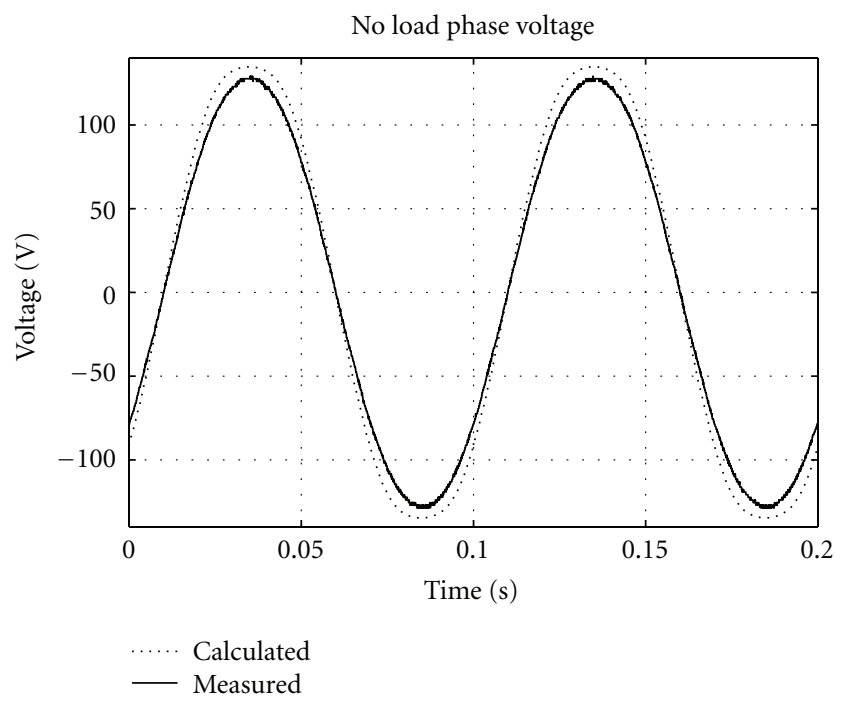

Figure 4: The voltage across one of the phases under no load conditions and at nominal speed of $10 \mathrm{rpm}$.

TABle 2: No load tests.

\begin{tabular}{lccc}
\hline No load tests & Simulations & Experiments & Difference \\
\hline Line voltage (peak) & $251 \mathrm{~V}$ & $228 \mathrm{~V}$ & $9 \%$ \\
Line voltage (rms) & $176 \mathrm{~V}$ & $158 \mathrm{~V}$ & $10 \%$ \\
Phase voltage (peak) & $134 \mathrm{~V}$ & $128 \mathrm{~V}$ & $4 \%$ \\
Phase voltage (rms) & $101 \mathrm{~V}$ & $92 \mathrm{~V}$ & $9 \%$ \\
\hline
\end{tabular}

4.2. Nominal Load Experiments. The generator load tests were carried out at the nominal speed of $10 \mathrm{rpm}$ and with a Y connected load of $4.44 \Omega /$ phase. The magnetic field was measured in the same way as in the no load test case. The measured normal component of the magnetic field is shown in Figure 5. Also shown in Figure 5 are the magnetic fields 


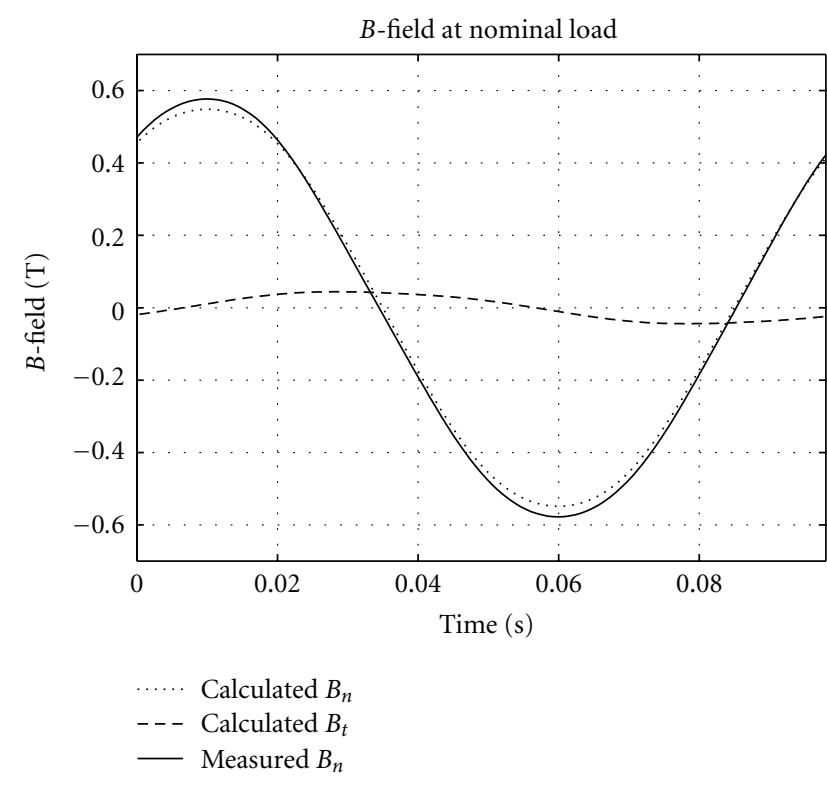

FIGURE 5: The magnetic field components in the air gap for nominal load and speed conditions ( $4.44 \Omega /$ phase and $10 \mathrm{rpm})$.

in the air gap predicted by the simulations under the same load conditions on the designed generator at a point $1 \mathrm{~mm}$ in front of the stator tooth.

It is found that the calculated maximum normal and tangential components of the magnetic field in the air gap are around $0.6 \mathrm{~T}$ and $0.04 \mathrm{~T}$, respectively. As far as the differences in the magnetic fields under no load and load conditions are concerned, it is seen that the normal component of the magnetic field is not significantly affected by either load conditions at nominal speeds. The force per unit area in the air gap at nominal load operation is about $63 \mathrm{kN} / \mathrm{m}^{2}$ according to simulations.

The phase voltages and phase currents measured under load conditions are shown in Figures 6 and 7, respectively, together with corresponding values predicted by simulations. The differences in the rms value of simulated and measured voltages and currents are shown in Table 3. From the data in Figure 6, it is found that the differences between the simulated and the measured rms voltages at nominal load are less than 1\%. However, from Figure 7 it is seen that the differences between the simulated and measured rms currents are around $4 \%$. The currents were measured using a universal power clamp Metrix MX240 [19]. A four channel Lecroy Wavesurfer 424 oscilloscope [20] was used for all the voltage and current measurements.

To quantify the harmonic contents in the machine, the measured voltages and currents were Fourier transformed. The measurements were made at sampling frequencies greater than ten times the highest harmonic (the 5th) found in the simulations. Only the fundamental and third harmonic components are seen in the measured nominal load currents and voltages. The simulations predict a negligible fifth harmonic as well. In terms of percentage, the third harmonic in the measured current and voltage at nominal

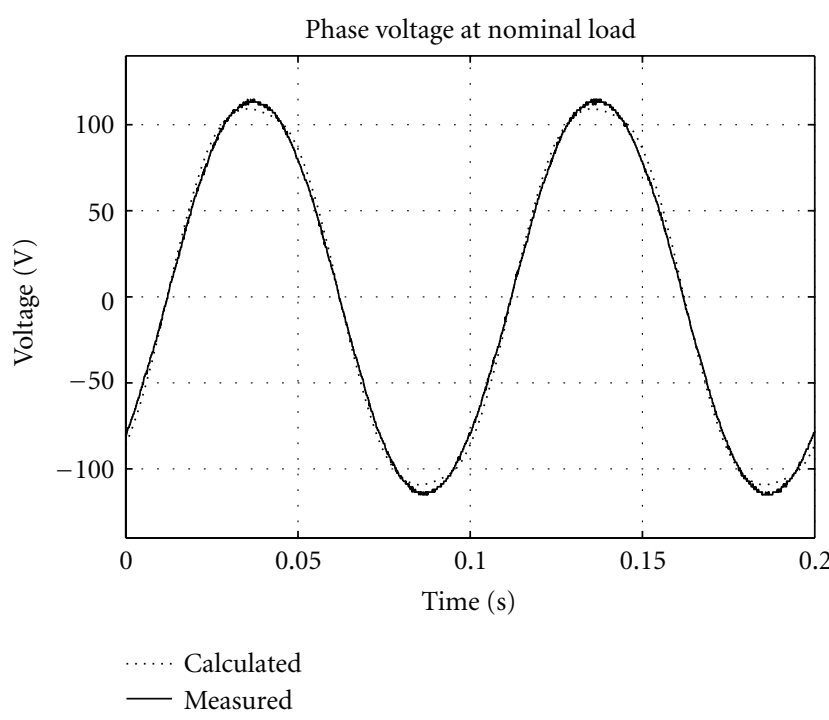

FIGURE 6: Voltage at nominal load across one of the phase resistor of $4.44 \Omega$ at nominal speed of $10 \mathrm{rpm}$.

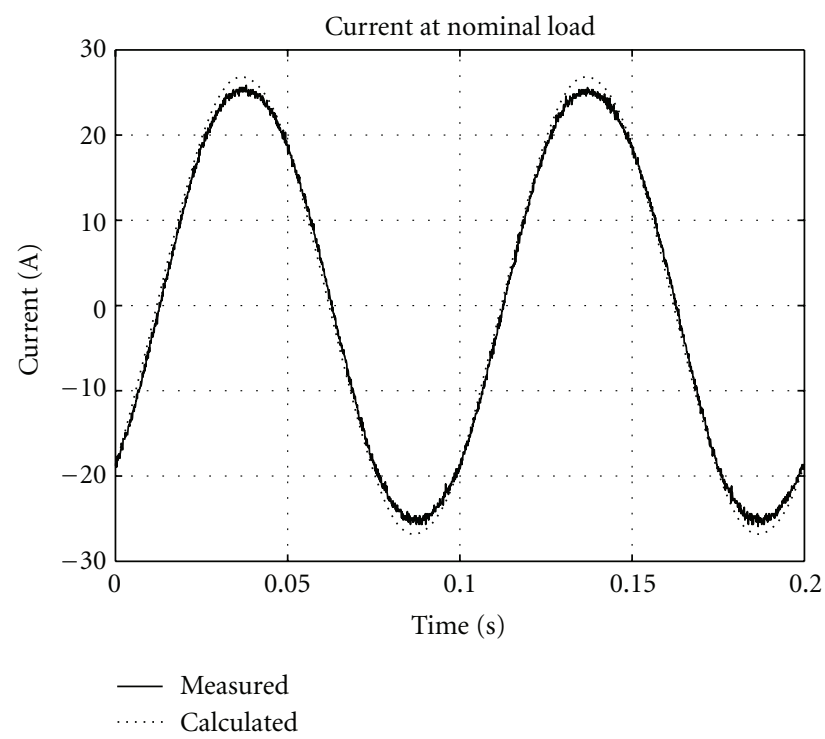

Figure 7: Measured and calculated current at nominal load $(4.44 \Omega)$ and nominal speed of $10 \mathrm{rpm}$.

load is $2 \%$, while the simulations predict $6 \%$. Table 4 shows the harmonic content in the phase voltage at nominal load and no load conditions.

The differences in the measured and simulated harmonics could be due to constructional and modeling inaccuracies or differences. It is preferable to keep the harmonics in the machine low as they cause additional losses in the machine core and in the copper. Moreover, in the future this type of generator will be connected to a rectifier. The role of harmonics for variable speed operation of a synchronous generator connected to a diode rectifier is further discussed in [21]. 
TABle 3: Nominal load tests.

\begin{tabular}{lccc}
\hline $\begin{array}{l}\text { Nominal load and } \\
\text { speed tests }\end{array}$ & Simulations & Experiments & Difference \\
\hline Line voltage (peak) & $202.8 \mathrm{~V}$ & $203.1 \mathrm{~V}$ & $0.1 \%$ \\
Line voltage (rms) & $143.5 \mathrm{~V}$ & $140.6 \mathrm{~V}$ & $2.0 \%$ \\
Phase voltage (peak) & $109.1 \mathrm{~V}$ & $114.1 \mathrm{~V}$ & $4.5 \%$ \\
Phase voltage (rms) & $82.2 \mathrm{~V}$ & $81.7 \mathrm{~V}$ & $0.6 \%$ \\
Phase current (peak) & $26.8 \mathrm{~A}$ & $25.8 \mathrm{~A}$ & $4.1 \%$ \\
Phase current (rms) & $18.9 \mathrm{~A}$ & $18.2 \mathrm{~A}$ & $3.7 \%$ \\
\hline
\end{tabular}

TABLE 4: Voltage harmonics.

\begin{tabular}{lcc}
\hline Order of voltage harmonics & Simulation & Experiment \\
\hline 3rd & $4.5 \%$ & $2 \%$ \\
5 th & $0.7 \%$ & $0 \%$ \\
\hline
\end{tabular}

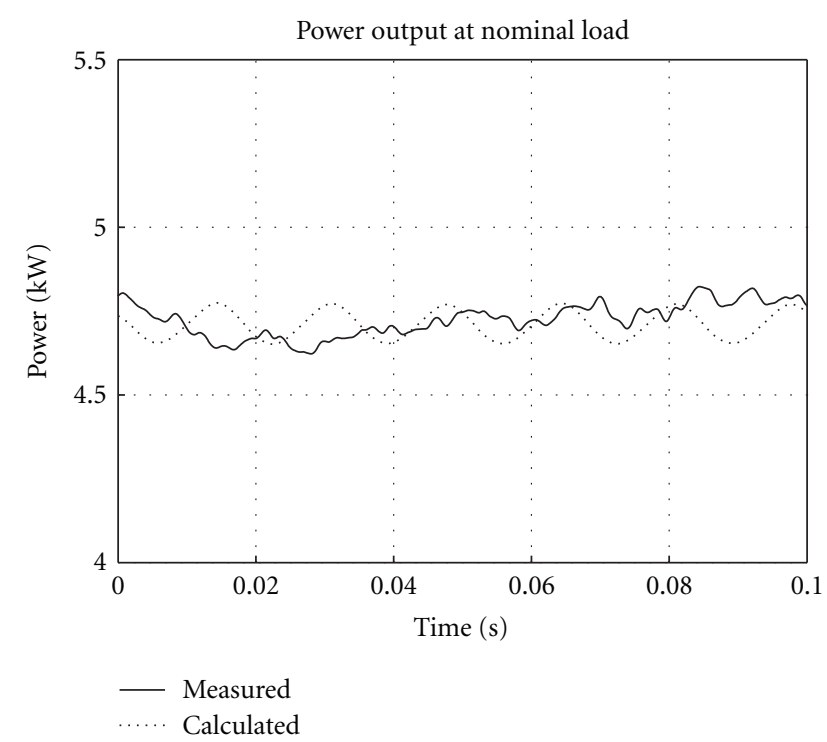

Figure 8: Power delivered to the load under nominal load and speed conditions.

TABle 5: Simulated losses and efficiency.

\begin{tabular}{lcc}
\hline$P_{\mathrm{Fe}}$ & Iron losses & $0.25 \mathrm{~kW}$ \\
$P_{\mathrm{Cu}}$ & Copper losses & $0.53 \mathrm{~kW}$ \\
$\eta$ & Efficiency & $85.5 \%$ \\
\hline
\end{tabular}

The power delivered to the nominal load at $10 \mathrm{rpm}$ is about $4.7 \mathrm{~kW}$ (see Figure 8). The electromagnetic losses in the generator from the simulations are presented in Table 5. The copper losses from the measured currents and resistances are about $0.5 \mathrm{~kW}$ and agree well with simulations. The simulations predict an efficiency of about $86 \%$ at nominal conditions for this generator.

4.3. Simulation of Variable Speed Operation. In order to show the generator's ability to control and brake the turbine at the different flow velocities that can occur in rivers or tidal

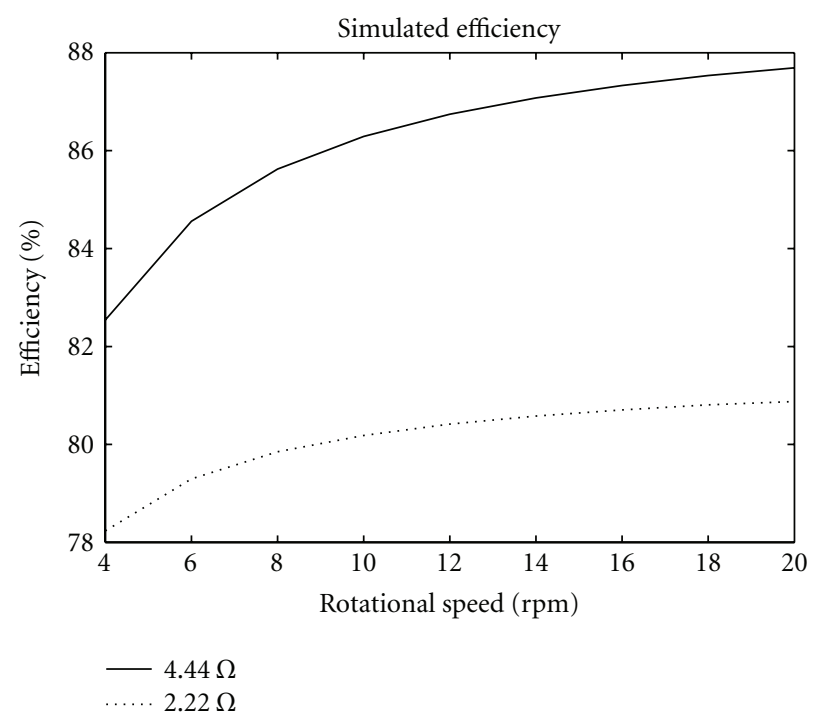

Figure 9: Efficiency at nominal load $(4.44 \Omega)$ and $2.22 \Omega$ in the range of 4-20 rpm.

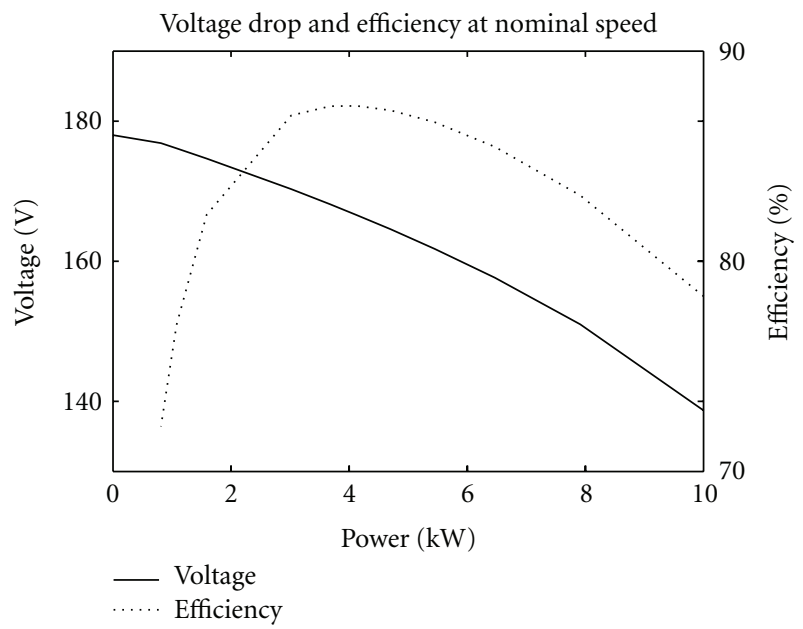

FIGURE 10: The line voltage and efficiency at increasing power for a constant rotational speed of $10 \mathrm{rpm}$.

currents, the efficiency of the generator at variable speed has been simulated and is shown in Figure 9 for nominal load and a load of $0.5 \mathrm{pu}$. It can be seen that the designed machine's efficiency is in the range of $78 \%-88 \%$ in the speed range of 4-20 rpm. Since the differences in the simulations and measurements for the cases discussed earlier are small, the actual efficiency of the experimental generator can be expected to be in the same range. That would allow for electrical control of the turbine while maintaining a good working efficiency. As a comparison, simulations of the line voltage drop and efficiency at nominal speed and varying load is shown in Figure 10. It can be seen that the armature reaction is low and that the generator can be used to control the turbine with only a small decrease in efficiency.

In the actual marine environment the efficiency of the total system depends on the power coefficient $C_{p}$ of 


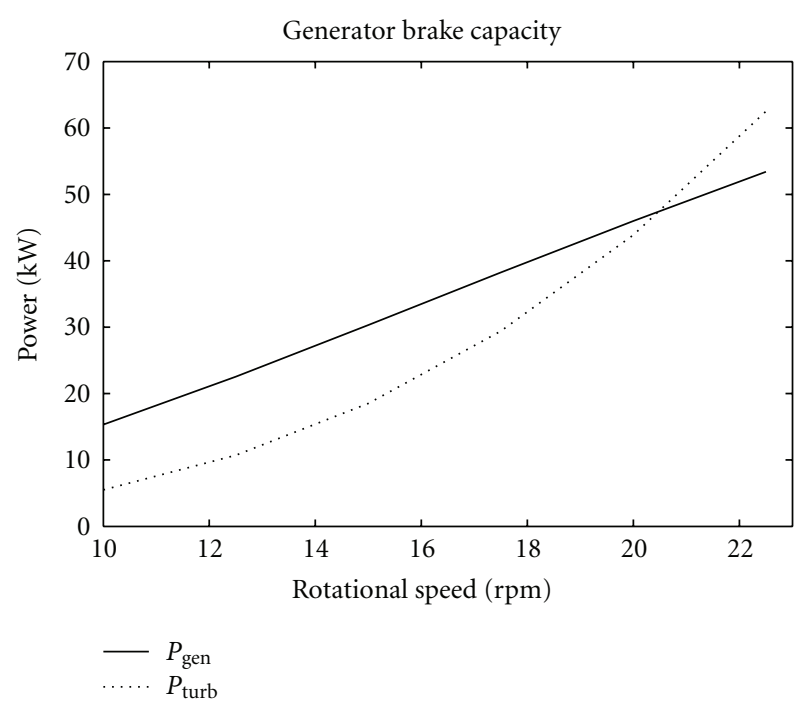

FIgURE 11: The generator electrical output with a dump load of $1.5 \Omega$ compared with the mechanical power from the turbine at fixed tip speed ratio operation.

the turbine. The anticipated control of the system is to keep a fixed tip speed ratio (TSR), hence keeping the optimum $C_{p}$ for the turbine without exceeding the cavitation limits by controlling the generator load. At higher velocities, the generator will keep the turbine at a lower TSR (and thus lower $C_{p}$ ) to limit the power absorbed by the turbine. Hence the generator will be run at both varying speeds and loads to control the TSR of the turbine. This control strategy has been effectively implemented in the case of wind power systems $[22,23]$.

Another important design criterion is the capacity of the generator to efficiently brake the turbine in the intended range of operation to exclude the use of blade pitch and mechanical brakes. To illustrate this, the generator has been simulated with a resistive dump load of $1.5 \Omega$ and compared to the power delivered from a hypothetical vertical axis turbine $\left(C_{p}\right.$ of 0.35 , delivering $5 \mathrm{~kW}$ at $10 \mathrm{rpm}$ in a water current of $1.5 \mathrm{~m} / \mathrm{s}$ ) running at a fixed TSR at increasing water velocities, see Figure 11. It can be seen that the generator safely brakes the turbine at velocities up to twice the nominal speed.

\section{Conclusions}

In this paper the electrical tests on a $5 \mathrm{~kW}, 10 \mathrm{rpm}$, permanent magnet cable wound direct drive generator for marine current energy conversion are presented. No load and nominal load tests were compared with the corresponding finite element simulations using the designed generator. In both tests, the magnetic field distributions in the air gap were also compared. It is found that the differences between the experiments and calculations are less than $10 \%$. Harmonic analyses show the presence of $2 \%$ third harmonic content. The efficiency of the designed machine is $78 \%-88 \%$ in the speed range of 4-20 rpm according to simulations. The low armature reaction and high overload capability show that the generator can be used to electrically control and brake the turbine in the intended range of operation.

\section{Acknowledgments}

Dr. Arne Wolfbrandt and Dr. Karl-Erik Karlsson are hereby acknowledged for development of the simulation tool. Sincere thanks to Ulf Ring for supervision and assistance during the construction work. Special thanks to Dr. Nelson Theethayi for interesting discussions, support, and encouragement during the time of writing. The experimental setup was funded by Vattenfall $\mathrm{AB}$ and the Swedish Centre for Renewable Electric Energy Conversion (financed by Uppsala University, The Swedish Agency for Innovation Systems (VINNOVA) and The Swedish Energy Agency (STEM)). The authors would also like to acknowledge the Swedish Research Council (grant no. 621-2009-4946).

\section{References}

[1] C. Versteegh, "Design of the Zephyros Z72 wind turbine with emphasis on the direct drive PM generator," in Proceedings of the Nordic Workshop on Power and Industrial Electronics (NORPIE '04), Trondheim, Norway, June 2004.

[2] 2011, http://www.winwind.com/.

[3] M. Dahlgren, H. Frank, M. Leijon, F. Owman, and L. Walfridsson, "WindformerTM. Wind power goes large-scale," $A B B$ Review, no. 3, pp. 31-37, 2000.

[4] R. Scott Semken, M. Polikarpova, P. Röyttä et al., "Direct-drive permanent magnet generators for high-power wind turbines: Benefits and limiting factors," IET Renewable Power Generation, vol. 6, no. 1, pp. 1-8, 2012.

[5] G. Ramtharan, N. Jenkins, and O. Anaya-Lara, "Modelling and control of synchronous generators for wide-range variablespeed wind turbines," Wind Energy, vol. 10, no. 3, pp. 231-246, 2007.

[6] P. Lampola, Directly driven, low-speed permanent-magnet generators for wind power applications [Ph.D. thesis], Helsinki University of Technology, 2000.

[7] J. Zhang, Z. Chen, and M. Cheng, "Design and comparison of a novel stator interior permanent magnet generator for directdrive wind turbines," IET Renewable Power Generation, vol. 1, no. 4, pp. 203-210, 2007.

[8] H. Polinder, M. E. C. Damen, and F. Gardner, "Design, modelling and test results of the AWS PM linear generator," European Transactions on Electrical Power, vol. 15, no. 3, pp. 245-256, 2005.

[9] M. Mueller, A. McDonald, K. Ochije, and J. Jeffrey, "A novel lightweight permanent magnet generator for direct drive power take off in marine renewable energy converters," in Proceedings of the 7th European Wave and Tidal Energy Conference, Porto, Portugal, September 2007.

[10] L. Drouen, J. F. Charpentier, E. Semail, and S. Clenet, "Study of an innovative electrical machine fitted to marine current turbines," in Proceedings of the Oceans 2007 Conferenc, Aberdeen, Scotland, June 2007.

[11] S. Benelghali, F. Mekri, M. Benbouzid, and J. F. Charpentier, "Performance comparison of three- and five-phase permanent magnet generators for marine current turbine applications under open-circuit faults," in Proceedings of the International 
Conference on Power Engineering, Energy and Electrical Drives (POWERENG '11), pp. 1-6, 2011.

[12] J. Clarke, G. Connor, A. Grant, C. Johnstone, and S. OrdonezSanchez, "Analysis of a single point tensioned mooring system for station keeping of a contra-rotating marine current turbine," IET Renewable Power Generation, vol. 4, no. 6, pp. 473487, 2010.

[13] M. Leijon and K. Nilsson, "Direct electric energy conversion system for energy conversion from marine currents," Proceedings of the Institution of Mechanical Engineers, Part A, vol. 221, no. 2, pp. 201-205, 2007.

[14] K. Thomas, M. Grabbe, K. Yuen, and M. Leijon, "A lowspeed generator for energy conversion from marine currentsExperimental validation of simulations," Proceedings of the Institution of Mechanical Engineers, Part A, vol. 222, no. 4, pp. 381-388, 2008.

[15] K. Yuen, K. Thomas, M. Grabbe et al., "Matching a permanent magnet synchronous generator to a fixed pitch vertical axis turbine for marine current energy conversion," IEEE Journal of Oceanic Engineering, vol. 34, no. 1, pp. 24-31, 2009.

[16] General Radio 1658 RLC Digibridge, Form: 1658-0120-D.

[17] 2011, http://fwbell.com/file/Gaussmeter\%20Catalog\%20\% 282011-01\%29.pdf.

[18] 2011, http://www2.tek.com/cmsreplive/psrep/13418/51W 17984_1_2011.01.19.17.28.13_13418_EN.pdf.

[19] 2011, http://www.chauvin-arnoux.com/display.asp?7987.

[20] 2011, http://www.lecroy.com/.

[21] I. Jadric, D. Borojevic, and M. Jadric, "Modeling and control of a synchronous generator with an active DC load," IEEE Transactions on Power Electronics, vol. 15, no. 2, pp. 303-311, 2000.

[22] J. F. Manwell, J. G. McGouan, and A. I. Rogers, Wind Energy Explained-Theory, Design and Application, John Wiley \& Sons, 2002.

[23] T. Wakui and R. Yokoyama, "A suitable load control method for constant tip speed ratio operation of stand-alone wind turbine-generator systems (part 1: Evaluation of power generation capability and output fluctuation)," Wind Engineering, vol. 31, no. 1, pp. 43-58, 2007. 

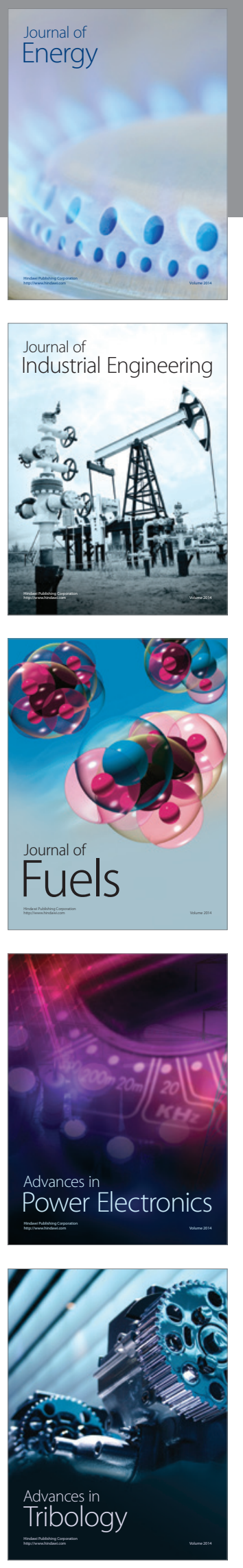
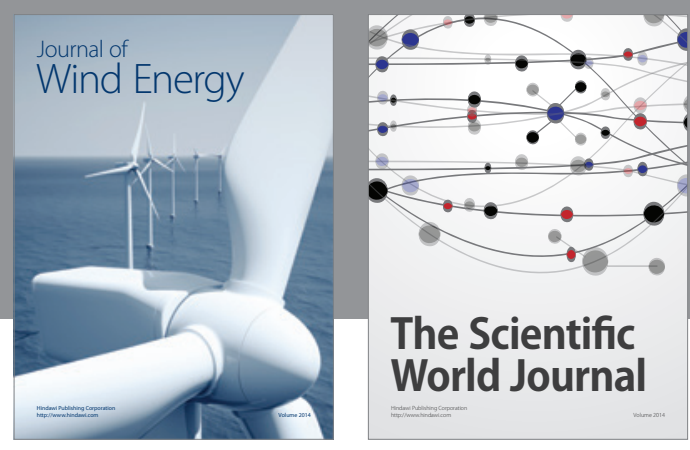

The Scientific World Journal

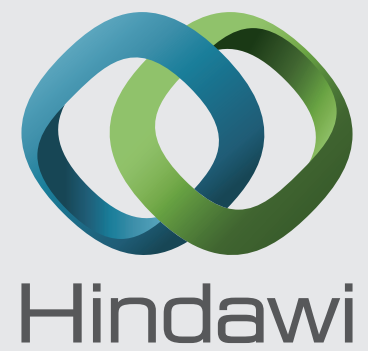

Submit your manuscripts at http://www.hindawi.com
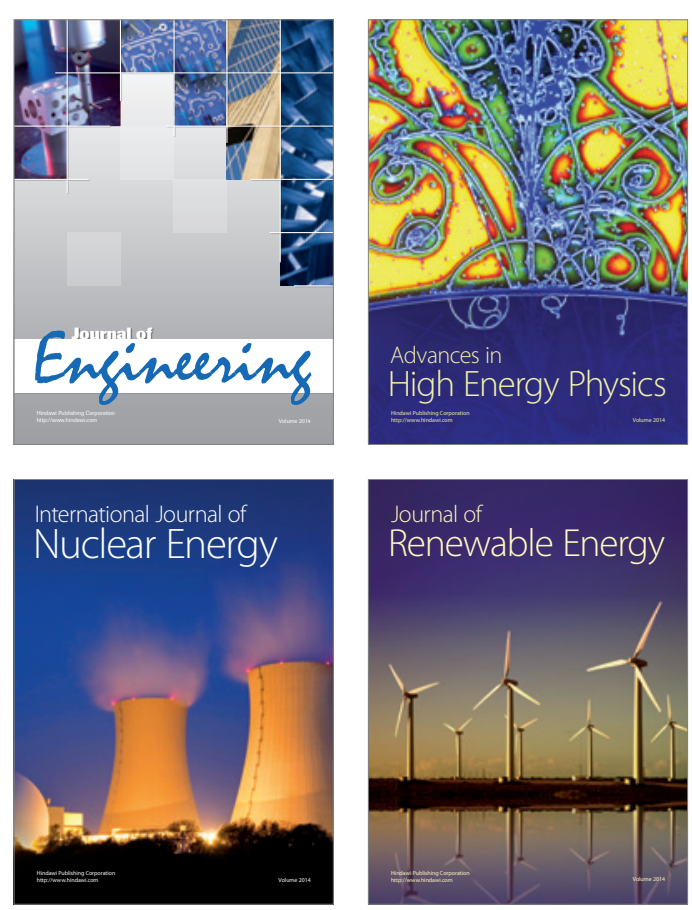

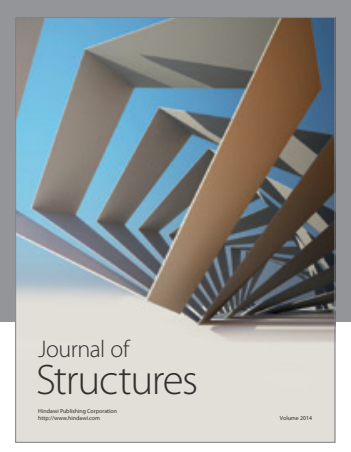

Rotating
Mechinery
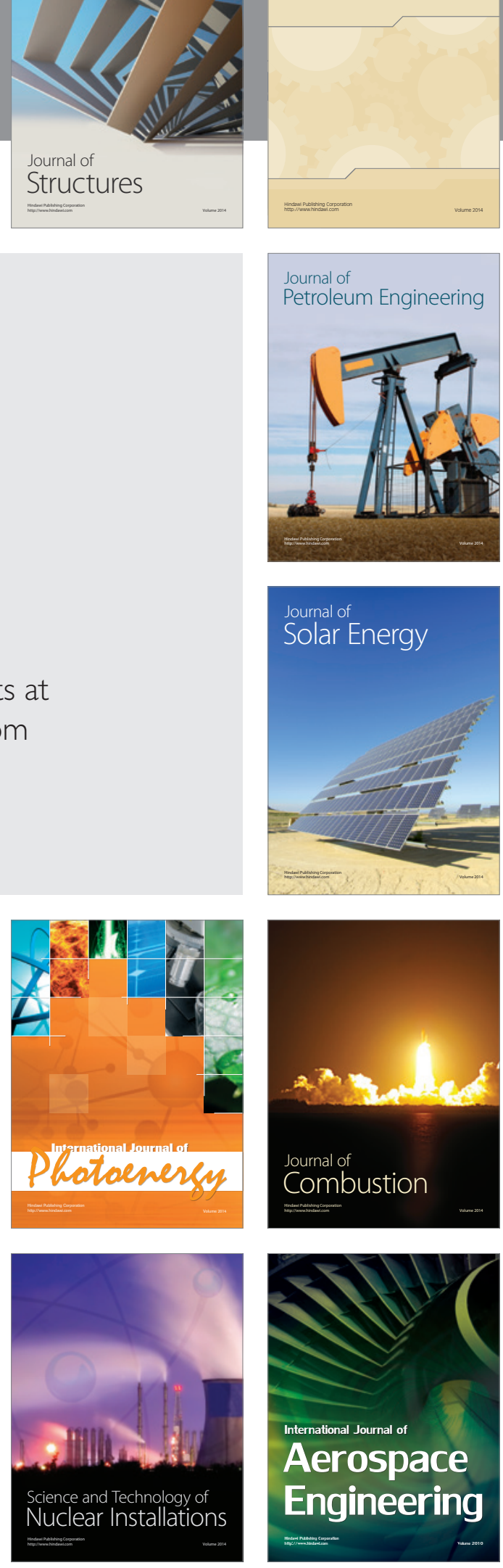